\title{
The Construction of Multimodal English Classroom for the Cultivating of Multiliteracy
}

\author{
Hu Huafang
}

School of Foreign Languages, Jiangxi Science and Technology Normal University, Nanchang, China,

1138559703@qq.com

Keywords: Multiliteracy; Multimodality; Classroom construction.

\begin{abstract}
One of the basic tasks of English teaching in the information age is to improve students' multiliteracies. The thesis introduces the concept of multiliteracy and multimodality and their relationship, and then it discusses the construction of multimodal English classroom for the cultivating of multiliteracy. By changing teaching notions, integrating teaching methods and making good use of the cooperation, consolidation and complement of different modes in multimodal English classroom, students' multiliteracies can be effectively improved.
\end{abstract}

\section{Introduction}

In the information age, diverse language acquisition channels and media are becoming resourceful, including books, pictures, Internet, audio, video, films, etc. Through the multiple media literacy knowledge and culture, students' ability of multiliteracies will determine their speed and depth of recognizing things. As an important cognitive ability in the information age, cultivating ability of multiliteracy becomes one of the important goals of modern education. This thesis discusses some ideas of building multimodal English classroom based on cultivation of multiliteracy, aiming to help students improve the ability of multiliteracy to adapt to the new requirements of social development.

In exploring the goal of modern education and the developing direction of literacy teaching, New London Group put forward the new concept of multiliteracy [1] which not only included the traditional reading and writing ability, but also included visual, hearing, smell, taste, space, posture, culture, and the information literacy and technology literacy and other reading abilities in the Internet age. Information literacy refers to the understanding of information resources, and ability of critically selecting and using all kinds of information resources to solve problems. As one of the most important kind of literacy ability, it is one of the basic qualities everyone should have in the modern society [2].We can predict that only high-quality talents who has both the traditional literacy and multiliteracies of information and technology literacy, can have sustainable survival and healthy development under diversified social and cultural background, can calmly face challenges of economic globalization, technology and language cultural diversity. Therefore, modern education should pay more attention to cultivating students' multiliteracy, which should become a national strategy. Traditional cognitive mode cannot adapt to the new requirements of social development, the renewal of the teaching and the reform of teaching mode is necessary[3,4].

In modern society, people often use a variety of symbols at the same time in communication to convey information and express meaning. Multimodality, also called multi-semiotic, includes many symbols such as spoken language, written language, graphics, images, colors, posture, space and other symbols resources which can be used to construct meaning [5,6]. With the development of science and technology, the mode of communication and communication media people use are changed greatly. The multimodal discourse is challenging the text which is in the center position in traditional communication. Mr. Kress [7] pointed out that, in textbooks, newspapers, reports, electronic media, and Internet, image is becoming a main alternative meaning building resources, or has equal status with language. People use a variety of symbolic resources to complete meaning representation and communication. Language and other symbol systems have their own strengths to 
cooperatively build meaning and serve for communication. In English teaching, if various symbol system of meaning potential can be fully explored, different modal coordination can be used, strengthened and complemented each other to build multimodal English class, the teaching effect will be improved greatly, the students' multiliteracies will be developed.

\section{Modes of cultivating multiliteracy}

Multiliteracy, as a product of rapid development of modern science and technology and cultural infiltration, focuses on seeking of information resources and application of various symbol systems including language resources. Cultivating multilliteracy is to overcome the shortcomings and the insufficiency of traditional language-centered teaching mode, to pay attention to acquiring language and culture by a variety of symbol systems, to emphasize important influence of multiple cultural differences on students in a specific context of using a variety of modes to convey meaning. New London Group [1], a pioneer of multimodal application in language teaching, believes that the main task of language teaching is to cultivate students' multilitercies and good applying multimodality. New London Group further put forward four specific teaching methods of multiliteracies, including situated practice, overt instruction, critical framing and transformed practice [8]. According to the above four methods, we believe that, to train students' multiliteracies, teachers and students must actively realize the change of role in the process of the interaction between "teaching" and "learning", make full use of multimedia network resources, pay attention to the diversification, personalization, arrangement of teaching mode and hypertext. Teachers in the information age should have a new attempt to reform classroom teaching mode, fully mobilize students' learning initiative and creativity, and cultivate their diversity, speaking, reading and writing ability and grasp of the multimodal significance, so as to improve the actual effect of teaching.

As educators, teachers' dominant role in class should be changed into a leading role, which means the knowledge-teaching-centered classroom teaching should be transformed into the independent knowledge-building-centered teaching mode in the network environment. Society has entered into the era of hypertext with multimodal tendency from the oral, reading and writing times. Media, network, communication are increasingly using symbol modes such as text, images, sound to express meaning, which proposes new requirements to teachers' classroom teaching and challenges that teachers cannot be content merely with cultivating the students' traditional reading and writing ability, but has the responsibility and obligation to focus on multiliteracy, enhance their own consciousness and the ability of multiliteracy, scientifically design multimodal teaching model according to the learners' background and the foundation of the actual situation to meet the diverse needs of cultivating students' multiliteracy.

Students must change the role of passive learning, and actively cooperate with the teacher, using the rich symbol resources to grasp the process of individual learning, create personalized learning conditions, explore the effective learning strategies, and improve their ability of multiliteracy, which is an expression ability of multimodal meaning. In the actual learning process, students' top priority is to transform a variety of symbolic resources offered in classroom into understanding and grasping overall significance produced by mutual coordination of the image, text, color and movement modes. Then, students should be familiar with the channels of gaining various symbol resources, learn to use information from various sources, autonomously learn and solve the problem, and learn languages easily in the natural environment. In addition, to understand the meaning potential of symbols, and express meaning by creatively using various symbol systems, students have to learn to employ modern technology to serve meaning construction.

When teachers and students realize their role shift, the scientific design of multiliteracy training mode is necessary; the following factors should be taken into consideration:

1) Flexibility of the teaching mode and the students' own initiative;

2) Pay attention to the positive influence of modern technology of multimedia on the language learning, make full use of all kinds of advanced media and efficient communication mode produced by scientific and technological progress in the teaching; 
3) Teachers, acting as the leading role, encourage students to extend the new knowledge by independent exploration and collaborative learning, and to stimulate the potential of the active meaning construction. Only through the joint efforts of teachers and students can we build efficient mode of multiliteracy, help the students raise traditional literacy to multiliteracy, and improve the comprehensive expression ability and cognitive ability.

\section{Construction of multimodal English class}

English teaching attaches great importance to cultivating students' communicative competence in real context. Multimedia technology presents a more specific context for students by providing sound, image, video, etc. It is easier to understand and memorize the information obtained through multi-channel discourse than single mode discourse, thus improving teaching efficiency. When constructing multimodal English class, the choice of mode and integration should fully consider whether it can offer real communicative situations as much as possible and convenient teaching conditions; whether it can offer beneficial assistance for classroom teaching; whether it can provide multimodal communication with multimodal discourse expression $[9,10]$. In the concrete teaching practice, teacher's choice of modality should be based on field of teaching content and the nature and genre of the curriculum; students' personality, the existing knowledge structure, interest, autonomous learning ability and the relationship between teachers and students, etc. should be considered; the teaching facilities and conditions such as device configuration, classroom environment, media and channels should be noticed.

Unsworth [11] put forward the concept of complementarity when discussing the mutual relationships of multimodal discourse forms. When a mode cannot fully express the meaning of the communicator, other modes should be added to supplement to make the meaning more complete and easy to understand. English teachers should fully understand the advantages and characteristics of meaning expression of various modes in the design of multimodal class courseware. On the basis of scientific use and integration of audio, video, font, color, brightness, layout and other elements, using different modal coordination, teachers can strengthen and complement each other to build a multimodal English classroom teaching. Specifically, when a mode is not enough to fully express meaning, just use other mode to complement the rest of the meaning, for example, captions can be provided for the picture. If a mode has an overall modal expression, use other mode to highlight the significance of parts, for example, the stress can be used in spoken language; bold can be used to emphasize important information when writing. When a mode is difficult to clearly express abstract, generalization or esoteric things, provide examples and illustration with other modes, for example, the simplified diagram can be used to express theory framework, flow chart can be used to express the process. Good teaching effect can be achieved through scientific selection and collocation of modal to enhance its positive effect. Of course, as for a particular discourse, how to express effectively by using the modal and the media forms is the long-term exploring topic in the future teaching practice.

Finally, starting from developing the students' multiliteracy, and based on teaching practice, the author proposes some ideas to construct the multimodal English classroom, which needs continuous development and optimization in the practical teaching.

\subsection{Role Transformation}

English teachers should transform the dominant role of the classroom into an orientative role to encourage students to become the main body of autonomous learning. Learning behavior includes three steps: information acquisition, information processing and information sending. Teachers must be good at using words, images, colors, sounds, and movements, taste and other modes to construct meaning and simulate the scene, and stimulate the learners' various sensory such as vision, hearing, touch, smell and taste, guide students to deal with the various sensory information such as visual and auditory information to gain a comprehensive understanding of the meaning. Teachers use multiple symbol resources to build open task-based teaching scenes, vividly impart knowledge by using coordination, strengthening and complementarity of different modes, in order to stimulate students' interest, to improve the internalization of students' learning, and to improve the persistence of 
memory. Knowledge storage is not enough, and more important step in learning behavior is the information sending. Teachers should help students understand meaning potential of all kinds of modality and their advantages and characteristics when working together to create meaning, and provide a lot of practice opportunities, such as writing, speech, reporting, debates, etc., to improve various skills like listening, speaking, reading, writing and translating ability, and physical ability, becoming effective origin of multimodality, rather than just passive recipients.

\subsection{Make multimodal PPT presentation courseware}

Multimodal PPT presentation, a compound discourse achieving the overall meaning through interaction of a variety of symbol system, belongs to the category of multimodal discourse [12]. With the wide use of computer and the popularization of network technology, the multimodal PPT presentation is increasingly gaining the favorite of teachers and students and becoming one of the teaching means with the most modern characteristic. English teachers should learn about the advantages and characteristics in various forms of modal meaning expression in the design of multimodal PPT presentation. Then, sound, image, color and other elements are scientifically used and integrated to achieve the best teaching effect. Multimodal PPT presentation will also help activate teaching atmosphere, improve students' learning attitude and enhance the enthusiasm and initiative of class participation.

\subsection{Utilize network resources.}

Modern society is characteristic of enormous information network resources and rapid updating; therefore, utilizing network resources plays a great role in promoting teaching. Through the powerful resource via the Internet, teachers can get multimodal material such as video, audio, images, graphics, and animation to prepare the courseware. Network can be used to build the teaching platform, upload a lot of teaching materials, improve the capacity and update knowledge, which make students complete autonomous learning through the network at any time. In addition, teachers can also establish teaching BBS to learn about students' learning situation and the demand, and make dialogues and exchange views with students.

\subsection{Create and perform English short play in class.}

“Acting” can develop the students' multiliteracies. English teachers guide students to adapt to the script and give performances, help students understand the underlying motives behind the character language and behavior, understand different meaning expressed by symbols like stage setting, props and costumes, color, sound, character expression, guide students move from "practical training" to "changing training", and improve multiliteracy of employing multimodal symbol resources to build meaning in the real life.

\section{Summary}

Multiliteracy is a new requirement for learners' literacy in the knowledge-based society. Due to social development, teachers have to change the teaching notions, update traditional teaching modes, construct the multimodality of classroom based on the multiliteracy training, make full use of the synergy, strengthening, and complementarity of different modes to impart knowledge, improve the teaching effect, guide the students learn and think creatively in multimodal and diverse environment. It is believed that the cultivation of multiliteracy of English education will have fruitful results through updating ideas and implementing specific measures.

\section{Acknowledgement}

This research was financially supported by the Jiangxi Postgraduate Teaching Reform Project (Project NO. JXYJG-2014-074) 


\section{References}

[1] The New London Group. A pedagogy of multiliteracies: Designing social futures, pp. 60-90,1996.

[2] Wei Qinhong. A Study on Improving College Students' Multiliteracies with Hypertextualization and its Training Models[J] Journal of Hangzhou Dianzi University (Social Sciences), 2010(4):44-47.

[3] $\mathrm{Hu}$ Zhuanglin. Multimodalization in Social Semiotics[J]Foreign Language Teaching and Researching, pp.1-10,2007(1).

[4] Zhu Yongsheng. Multiliteracy and its Enlightenment on Chinese Teaching Reform, Foreign Language Research, pp. 10-14,2008(4).

[5] O’Halloran K L. Multimodal Discourse Analysis: Systemic Functional Perspectives,2004.

[6] Baldry A P, Thibault P. Multimodal corpus linguistics, Thompson G, Hunston S. System and Corpus: Exploring Connections, pp. 164-183, 2006.

[7] Kress G. Sociolinguistics and social semiotics, Cobey P. The Routledge Companion to Semiotics and Linguistics, pp. 66-82, 2001.

[8] The New London Group. A Pedagogy of Multiliteracies: Designing Social Futures, Cope B, Kalantzis Mleds. Multiliteracies: Literary Learning and the Design of Social Futures. pp. 9-38,2000.

[9] Zhang Delu. Application of Multimodal Discourse and Media Technology, Foreign Language Research, pp.15-20,2009(4).

[10]Zhang Delu, Wang Lu. The Synergy of Different M odes in Multimodal Discourse and Their Realization in Foreign Language Teaching, Foreign Language Research, pp. 97-102,2010(2).

[11]Unsworth L.E-literature for Children: Enhancing Digital Literacy Learning,2006.

[12]Zhang Zheng. A Co-relational Study of Multimodal PPT Presentation and Students' Learning Achievements, Foreign Languages in China, pp.54-58,2010(3). 